Overall cost of SC-TNFi treatment: Non-persistent $11218.81 €(6444.32)$, persistent $10470.19 €(3465.48) ; p=0.658$.

Table 1. HCRU costs

\begin{tabular}{|c|c|c|c|c|}
\hline & Non-persistent $(\mathrm{n}=25)$ & Persistent $(n=85)$ & $\operatorname{Total}(\mathrm{n}=110)$ & $\mathrm{P}$ \\
\hline \multicolumn{5}{|c|}{ HCRU costs 12 months prior to SC-TNFi initiation, $€(S D)$} \\
\hline Outpatient care & $243.48(828.86)$ & 87.17(293.61) & $122.70(471.20)$ & 0.204 \\
\hline $\begin{array}{l}\text { Rheumatology outpa- } \\
\text { tient care }\end{array}$ & $216.39(169.88)$ & $174.79(101.06)$ & & 0.224 \\
\hline Inpatient care & $500.41(1542.93)$ & 170.34(846.47) & 245.36(1046.74) & 0.571 \\
\hline Emergency & 3 & & & 0.850 \\
\hline Laboratory testing & 376.12 & 388. & $385.46(20$ & 0.458 \\
\hline $\begin{array}{l}\text { Other non-biological } \\
\text { therapies }\end{array}$ & 10.77(39.83) & $36.79(250.55)$ & $30.88(221.01)$ & 0.803 \\
\hline Total & 1384.94(1816.17) & $896.60(1247.60)$ & $1007.59(1402.87)$ & 0.299 \\
\hline \multicolumn{5}{|c|}{ HCRU costs 12 months post SC-TNFi initiation, $€(\mathrm{SD})$} \\
\hline Outpatient care & $106.11(172.85)$ & $76.67(112.90)$ & $83.36(128.67)$ & 0.682 \\
\hline $\begin{array}{l}\text { Rheumatology outpa- } \\
\text { tient care }\end{array}$ & $327.29(170.10)$ & $195.58(100.05)$ & $225.52(130.99)$ & $<0.00$ \\
\hline Inpatien & & & & 0.96 \\
\hline Emer & 89.1 & 36.06 & $48.12(125.31)$ & 0.198 \\
\hline Laboratory testing & 182.14(128.62) & $146.86(141.48)$ & $154.88(138.89)$ & 0.061 \\
\hline $\begin{array}{l}\text { Other non-biological } \\
\text { therapies }\end{array}$ & $3859.80(4043.86)$ & $25.89(116.05)$ & $897.24(2493.21)$ & $<0.00$ \\
\hline Total & 4653.84(4269.61) & $561.93(682.14)$ & 1491.91(2709.23) & $<0.0$ \\
\hline
\end{tabular}

Conclusion: - Non-persistence was observed in less than a quarter of the patients.

- No differences in the costs of SC-TNFi treatment were observed between the persistent and non-persistent groups, leading us to believe that persistence may not be associated with SC-TNFi costs offsets for patients with IMRD.

- During the period post SC-TNFi initiation, the costs of rheumatologic outpatient care and treatment with other non-biological therapies as well as total costs were statistically significantly lower in the persistent cohort. These results suggest that persistence may be associated with HCRU cost savings for IMRD patients.

Disclosure of Interests: None declared

DOI: 10.1136/annrheumdis-2021-eular.3510

\section{POS1417 DO SOCIAL FACTORS IMPACT ON BIOLOGICS COSTS IN RHEUMATOID ARTHRITIS? RESULTS FROM THE MOROCCAN RBSMR REGISTRY}

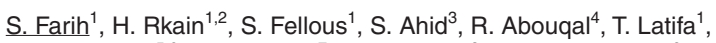
I. Hmamouchi ${ }^{5,6}$, L. Achemlal ${ }^{7}$, I. El Bouchti ${ }^{8}$, A. EL Maghraoui ${ }^{9}$, I. Ghozlani ${ }^{10}$, H. Hassikou ${ }^{11}$, T. Harzy ${ }^{12}$, I. Linda ${ }^{13}$, O. Mkinsi ${ }^{14}$, R. Niamane ${ }^{15}$, R. Bahiri ${ }^{16}$, F. Allali ${ }^{1}{ }^{1}$ El Ayachi Hospital, Ibn Sina University Hospital, Department of Rheumatology B, Salé, Morocco; ${ }^{2}$ Faculty of Medicine and Pharmacy of Rabat, Mohammed V University, Physiology Laboratory, Rabat, Morocco; ${ }^{3}$ Mohammed V University, Research Team of Pharmacoeconomics \& Pharmacoepidemiology, Rabat, Morocco; ${ }^{4}$ Faculty of Medicine and Pharmacy, Mohammed V University, Laboratory of Biostatistical, Clinical and Epidemiological Research, Rabat, Morocco; ${ }^{5}$ Faculty of Medicine and Pharmacy, Mohammed V University, Laboratory of Biostatistical, Clinical and Epidemiological Research, Rabat, Morocco; ${ }^{6}$ Provincial Hospital of Temara, Department of Rheumatology, Temara, Morocco; ${ }^{7}$ Military Hospital Mohammed V, Ibn Sina University Hospital, Department of Rheumatology, Rabat, Morocco; ${ }^{8}$ Arrazi University Hospital, Department of Rheumatology, Marrakech, Morocco; ${ }^{9}$ Private Medical Office, Private Medical Office, Rabat, Morocco; ${ }^{10}$ Department of Rheumatology, University Hospital, Agadir, Morocco; ${ }^{11}$ Military Hospital Moulay Ismail, Hassan II University Hospital, Department of Rheumatology, Meknès, Morocco; ${ }^{12}$ Hassan II University Hospital, Department of Rheumatology, Fes, Morocco; ${ }^{13}$ Mohammed VI University Hospital, Department of Rheumatology, Oujda, Morocco; ${ }^{14}$ Ibn Rochd University Hospital, Department of Rheumatology, Casablanca, Morocco; ${ }^{15}$ Military Hospital Avicenne, Mohammed VI University Hospital, Department of Rheumatology, Marrakech, Morocco; ${ }^{16} \mathrm{El}$ Ayachi Hospital, Ibn Sina University Hospital, Department of Rheumatology A, Salé, Morocco

\section{Background:}

Objectives: The aim of this study was to estimate the annual direct cost of biologics in rheumatoid arthritis and to evaluate the impact of social factors on biological use and costs.

Methods: Patients in the Moroccan register of biologicals (RBSMR) with available 1-year data were included. Variables related to socio-economic status, disease and biological were collected. Direct costs included prices of biologics, costs of infusions, and subcutaneous injections. Biological use and costs were compared based on social factors.

Results: Our study included 197 patients (female sex of $86.8 \%$, mean age of $52.3 \pm 11$ years). Patients were on one of the following therapies: Rituximab
( $n=132)$, Tocilizumab $(n=37)$ or TNF-blockers $(n=28) .44 .2 \%$ of included patients have the RAMED medical assistance (health insurance scheme for the economically underprivileged). Illiteracy was noted in $45.7 \%$ of cases. Median one-year direct costs per patient were €1,665 [€1,472 - €9,879].

There was no statistically significant difference in costs between men and women $(p>0.05)$, between illiterate and literate $(p>0.05)$. There was a statistically significant difference in costs between patients with the RAMED medical assistance scheme and other health insurances $(p<0.01)$.

Conclusion: This study showed that Moroccan RA patients had equal access to biologics regardless of their gender or level of education. Indeed, the insurance system influence the costs of biologics. Accessibility of those expensive treatments in a developing country seems be explained by efforts of the Moroccan ministry of health who has allocated a substantial budget for biologic DMARDs for patients with RAMED in the tertiary structures in our country.

Disclosure of Interests: None declared

DOI: 10.1136/annrheumdis-2021-eular.4225

\section{Epidemiology, risk factors for disease or disease progression}

\begin{tabular}{l|l}
\hline POS1418 & REALIZING EARLY RECOGNITION OF ARTHRITIS IN \\
TIMES OF INCREASED TELEMEDICINE: THE VALUE \\
OF PATIENT-REPORTED SWOLLEN JOINTS
\end{tabular}

C. Rogier ${ }^{1}$, B. Van Dijk², E. Brouwer ${ }^{3}$, P. De Jong ${ }^{1}$, A. Van der Helm - van Mil ${ }^{1,2}$. ${ }^{1}$ Erasmus MC, Department of Rheumatology, Rotterdam, Netherlands; ${ }^{2}$ Leiden University Medical Center, Department of Rheumatology, Leiden, Netherlands; ${ }^{3}$ University Medical Center Groningen, Department of Rheumatology, Groningen, Netherlands

Background: Early diagnosis and management of patients with inflammatory arthritis $(\mathrm{IA})$ are critical to improve long-term patient-outcomes. Assessment of joint swelling at joint examination is the reference of IA-identification; early access clinics are constructed to promote this early recognition of IA. However, due to the COVID-19 pandemic the face-to-face capacity of such services is severely reduced. The accuracy of patient-reported swelling in comparison to joint examination has been extensively evaluated in established RA ( $\rho$ 0.31-0.67), but not in patients suspected for IA.[1]

Objectives: To promote evidence based care in the era of telemedicine, we determined the accuracy of patient-reported joint swelling for actual presence of IA in persons suspected of IA by general practitioners(GP).

Methods: Data from two Dutch Early Arthritis Recognition Clinics were studied These are screening clinics (1.5-lines-setting) where GPs send patients in case of doubt on IA. At this clinic patients were asked to mark the presence of swollen joints on a mannequin with 52 joints. For this study the DIP joints and the metatarsal joints were excluded and, therefore, a total of 42 joints were assessed for self-reported joint swelling. Clinically apparent IA of $\geq 1$ joint determined by the physician was the reference to calculate sensitivity, specificity, positive and negative likelihood ratios (LR+,LR-), and positive and negative predictive values (PPV, NPV) on patient-level. Pearson correlation coefficients $(\rho)$ were determined. Predictive values depend on the prevalence of a disease in a population. Because the prevalence of IA in a 1.5-lines-setting will differ from a primary care setting, post-test probabilities of IA were estimated for two lower prior-test probabilities as example, namely $20 \%$ (estimated probability in patients GPs belief IA is likely) and $2 \%$ (prior-test probability with less preselection by GPs), using likelihood ratios and nomograms.

Results: A total of 1637 consecutive patients were studied. Median symptom duration was 13 weeks. $76 \%$ of patients marked $\geq 1$ swollen joint at the mannequin. $41 \%$ of patients had $\geq 1$ swollen joint at examination by rheumatologists. $\rho$ was 0.20 (patient-level)-0.26(joint-level).

The sensitivity of patients-reported joint swelling was high, $87 \%$, indicating that the majority of patients with IA had marked swelling on the mannequin. However the specificity was $31 \%$, indicating that $69 \%$ of persons without IA had also done so. The LR+ was 1.25; the LR- 0.43 . The PPV was $46 \%$, the NPV $77 \%$. Thus the PPV increased hardly (from $41 \%$ to $46 \%$ ) and the NPV somewhat (from $59 \%$ to $77 \%$ ). Also in settings with prior-test probabilities of $20 \%$ and $2 \%$, estimated PPVs (from respectively $20 \%$ and $2 \%$ to $24 \%$ and $2 \%$ ) and NPVs (from respectively $80 \%$ and $98 \%$ to $90 \%$ and $99 \%$ ) hardly increased.

Conclusion: Patient-reported joint swelling had little value in distinguishing patients with/without IA for different prior-test probabilities, and is less valuable in comparison to self-reported flare detection in established RA.

\section{REFERENCES:}

[1] Barton JL, Criswell LA, Kaiser R, et al. Systematic review and metaanalysis of patient self-report versus trained assessor joint counts in rheumatoid arthritis. J Rheumatol 2009;36:2635-2641.

Disclosure of Interests: None declared

DOI: 10.1136/annrheumdis-2021-eular.235 